\title{
The Tunnel Experience: Reality or Hallucination?
}

\author{
Kevin J. Drab
}

\section{INTRODUCTION}

Experiences of unusual states of awareness are important phenomenological resources whose contents may, when properly classified and analyzed, contain invaluable insights into the nature of the human mind. The topography of anomalous subjective events, however, often tends to be too complex and novel to communicate or study systematically. Therefore, if we wish to study reports of these experiences, we will have the most success if we begin by examining their less complex elements.

The sensation of moving through a tunnel-like space is an occasional occurrence in hallucinatory conditions, and has been reported in association with certain types of unusual experiences considered by many to be important contacts with other realms of reality or consciousness, e.g., out-of-body experiences (OBE) and near-death experiences (NDE) (Crookall, 1970; Moody, 1975; Green, 1968; Ring, 1980a). A typical example of such a tunnel experience (TE) can be found in this report of a twenty-seven-year-old Englishwoman whose heart failed: "I became less and less able to see and feel. Presently I was going down a long black tunnel with a tremendous alive sort of light bursting in at the far end. I shot out of the tunnel into this light. I was in the light, I was part of it, and I knew everything - a most strange feeling." 1

TEs are generally simple and consistent in their descriptions, permitting a fair degree of detailed study of their characteristics. Through such a study of reports of TEs in various states of awareness, significant clues may be found that could shed light on the more complex contents of these states and their underlying mechanisms.

The purpose of this study, then, is to perform a descriptive analysis of the TE based on the accounts of individuals who have had one and to discuss possible explanations for the experience. 


\section{METHOD}

\section{Data Collection}

I have collected approximately 1,112 reports of unusual experiences whose contents are of the type considered by many cultures to be visionary encounters with other modes of being related to conceptions of other worlds, death, afterlife, mysticism, or psychic forces. Most of the cases in this collection contain one or more of the following elements: otherworldly environments and beings, OBEs, deceased persons, varieties of light phenomena, mystical unity, intuitive knowledge, tunnel experiences, panoramic life reviews, and other phenomena seeming to reflect contact with another realm of existence. Although they lack publicly demonstrable reality, these experiences are distinguished by their perceptual and/or emotional vivacity, similarity in description, and apparent bearing on crucial questions concerning the nature of man, non-physical realities and post-mortem survival.

In selecting my case materials, I simply included all cases that contained the previously mentioned features. The cases were obtained from the following sources:

1. Personal interviews and correspondence.

2. Interviews and correspondence in the Archives of the (British) Society for Psychical Research.

3. Cases published in the literature (circa 1700 to 1981).

4. Case history material lent by Professor Kenneth Ring from his NDE files.

Published cases used included relevant reports in the collections of Barrett (1926), Myers (1903), Crookall (1961, 1964, etc. $)^{2}$, Muldoon and Carrington $(1929,1951)$, and numerous other compilations of reports. The collection can be considered a fairly comprehensive and representative sample of the types of unusual experiences that have concerned parapsychological investigators over the years.

Of the 1,112 cases in the original pool, 297 were not considered for this study (although many contained TE reports) because the medical categories under which they were subsumed (anesthetics without physiological complications, $\mathrm{CO}_{2}$ inhalation, minor and major psychedelics, and psychoses) contained too few cases and too many complicating variables to allow effective comparative analysis with reports in other categories. This elimination of valuable data was unavoidable; it is hoped that these problems will be overcome in future research and that these categories, particularly $\mathrm{CO}_{2}$ inhalation and anesthetics, will be studied. 


\section{Definition of Tunnel Experience}

Moody's (1975) study of NDEs classified reports of tunnels, dark spaces, vacuums, and voids under one heading ("dark tunnel"), as he believed that the experients were all trying to express the same idea "of being pulled very rapidly through a dark space of some kind." Other NDE researchers, such as Sabom and Kreutziger (1978) and Ring (1980a), also combined descriptions of dark dimensionless spaces with those of tunnel-like spaces. Garfield (1979) placed his emphasis on the contrasting themes of maximal freedom and maximal constriction that were expressed in his respondents' experiences of tunnels or voids. Crookall (1964) assumed that a transitional phase involving a "blackout of consciousness" occurred in OBEs, and considered descriptions of tunnel-like spaces to be the same as reports of outer space, black vacuums, voids, and unconsciousness.

Although a close relationship appears to exist between experiences of tunnel-like spaces and dark, empty spaces, the featureless and vague properties of the latter present little information for analysis or comparison. A good example of this can be found in the description of a severely ill woman: "I all at once felt myself soaring up into space. Faster and faster I went. Space was like a dark void, but it wasn't black. It was like nothing at all. I've never been able to find the right words to describe the void I flew through." 3

The problem is further compounded by the difficulty that an experient may have in discriminating between experiences of a dark visual field having a natural cause, such as closing one's eyes or syncope, and the actual perceiving of, or moving through, a dark space. In order to avoid additional confusion I decided that descriptions of empty spaces would not be considered in this study; as a result, I will concentrate here on descriptions of definite tunnel-like spaces.

The tunnel experience may be defined as the perception of a realistic enclosed area of space much longer than its diameter. The surrounding features and depth perspectives of this phenomenon imply an organization of the space around a central area in the visual field. Indeed, a centralized area of light or an opening is sometimes described at the "far end" of the space, but observation of a central point is not necessary in establishing a tunnel-like perspective. Descriptions using identifying words such as cylinder, pipe, tunnel, passage, corridor, spiral, well, funnel, shaft, hole, culvert, cave, long enclosure, sewer, cone, and so on, would be considered TEs. 
The methodological problems normally accompanying the use of anecdotal reports of unusual experiences (Krippner, 1970; Savage, 1975; West, 1948) were further complicated in this study by the frequent lack of complete biographical and medical information on cases gained from the Archives of the Society for Psychical Research and the general literature. Despite the lack of these data, the majority of cases contained sufficient details regarding their circumstances to permit their assignment to one of the following categories of general medical condition: 4

a. Cardiopulmonary arrest (CPA). The experient had either inadequate or total arrest of respiratory and/or circulatory functions with concomitant symptoms. It is assumed that if the natural course of the subject's condition had not been reversed by external resuscitative measures, irreversible cellular biochemical changes of biological death would probably have occurred. Cardiac arrest is manifested clinically by apnea, unconsciousness, dilated pupils, and the absence of heart sounds, pulse, and blood pressure. It may be due to ventricular fibrillation, uncoordinated contractions, cardiac standstill, or circulatory collapse with sudden hypotension due to vasodilation or hypovolemia. Respiratory arrest results from airway obstruction or respiratory depression, or may be secondary to cardiac arrest. Cyanosis (except in $\mathrm{CO}$ poisoning), and eventually dilated pupils and cardiac arrest, follows respiratory arrest. Of the 815 collected cases, 183 (22 percent) belong to the CPA category.

b. Severe stress (SS). 5 The experient was in a serious physiological condition resulting from disease, trauma, or stress, the natural progress of which, without medical intervention, might lead to CPA or permanent damage to the patient. This category would include near-drowning, coma, traumatic shock, severe toxic conditions, severe blood loss, and generally weakened conditions such as extended serious illness. Of the 815 collected cases, 220 (27 percent) belong to the SS category.

c. Mild stress (MS). ${ }^{5}$ The experient suffered a non-severe disturbed physiological condition resulting from disease, trauma, or other stresses that do not meet the CPA or SS category requirements. Sources of MS may be external, neurological, psychological, etc., as long as some degree of stress has been placed on the organism. This category would include minor injuries and pain, fatigue, mild fever, fainting, fear, and other strong but not extreme emotions, migraines, and mild toxic conditions. Of the total, 130 (16 percent) belong to the MS category.

d. Normal (NL). The experient was in a relatively healthy, unstressed physical or mental condition. This category would include 
normal waking states, relaxation, sleep, meditation, and hypnosis. Of the total, 282 ( 35 percent) belong to this category and are predominantly forms of out-of-body experiences.

Evaluation of Data

Since the study is descriptive in nature, sophisticated statistical procedures were not employed in the analysis. The material contained in the TE reports was instead grouped into common features that were then examined for frequencies and relationships among the variables of medical conditions and sex. Measurement of frequencies of various features is presented in discrete number and percentage values. Simple measures of association and chi-square analysis (corrected) were used to evaluate the significance of observed distributions, and the significance level of $\leqq .05$ (two-tailed) was selected for assessing results.

\section{RESULTS}

The pool of 815 cases yielded only 71 (9 percent) describing an element meeting the TE definition. The occurrence of so few reports in a pool of this size indicates that the TE was not a commonly reported feature in the general range of anomalous experiences under study. A significantly higher incidence of TEs was found, however, in the CPA category ( 20 percent) as compared with the SS ( 8 percent), MS (5 percent), and NL ( 4 percent) categories, suggesting that extreme physiological stress may be especially conducive to TEs (see Table 1).

Near-death experience (NDE) researchers have tended to include experiences occurring in CPA and SS categories under the general grouping of "near-death"; combining the CPA and SS cases yields a total of $54 \mathrm{TE}$ reports (13 percent) from a pool of 403 for this neardeath category. A significant difference was found between the frequency of cases in the near-death category and that found in the combination of the MS and NL categories (chi square $(1)=21.46$, p. < .001), which presents further support for the observation that TEs are more frequent in serious medical conditions than in nonserious conditions. ${ }^{6}$

The tendency of NDE researchers to classify descriptions of tunnellike spaces with descriptions of voids, black spaces, and darkness hampers comparison of their statistics with those of the present study. Ring (1980b), however, found 18 percent of his NDE cases mentioned "something like a tunnel"; my general impression is that other studies of NDEs have found the frequency of TEs to be similar to or less than Ring's results. 


\section{Medical Conditions}

Since heart attacks and mechanical accidents are two of the leading causes of death in America, it is not surprising to find that 48 percent of the CPA and SS cases were grouped under these conditions (see Table 1). Cancer and stroke rank as the second and third leading causes of death among Americans, yet no CPA or SS cases reported these medical conditions.

The absence of these conditions is notable, since cancer and cerebrovascular accidents are commonly associated with hallucinations and altered cognitive functions (Lipowski, 1980). This absence is particularly interesting in view of Osis and Haraldsson's (1977) finding that the largest number of terminal patients reporting apparitions, mood elevation, and visions of other worlds were those dying of cancer, followed by those dying of heart and circulatory diseases. The significance of there being no TEs reported by stroke cases is difficult to assess with the limited data available, but there is a possibility that it may offer a clue to the mechanisms producing the TE. Heart attacks, mechanical injuries, and the other conditions reported in the CPA and SS categories are typically acute (excepting pneumonia and inflammation cases in the "general illness" conditions), occurring in otherwise healthy individuals, and the chances of uncomplicated resuscitation and recovery are, therefore, considerably greater than those of patients with chronic conditions. If cases reporting "general illness" or "no specifics" are excepted, 74 percent of the cases in the CPA and SS categories underwent a sudden onset of the condition as opposed to an extended illness involving a slow decline in the patient's functions (e.g., cancer or wasting and degenerative diseases). This suggests the TE is more often triggered by a specific sudden change in the physiological state of the experient (such as an abrupt drop in blood pressure, or shock to the nervous system) and will be discussed more fully later in this paper.

Sex and Age

Reports found in the published literature failed on occasion to mention the experient's gender, as a result of which the sex of 12 TE cases is unknown; of the 59 known cases, 41 percent were male and 59 percent female. No significant differences were found in gender distributions in the medical categories and specific conditions.

The experient's age at the time of the TE was seldom reported, so this variable was not considered for inclusion. 
Table 1

Medical Conditions and Sex of TE Cases

\begin{tabular}{|c|c|c|c|c|}
\hline \multirow[b]{2}{*}{ General Category } & \multirow[b]{2}{*}{ Specific Condition } & \multicolumn{2}{|c|}{ Sex } & \multirow[b]{2}{*}{ Unknown } \\
\hline & & Male & Female & \\
\hline $\begin{array}{l}\text { a. Cardiopulmonary } \\
\text { arrest (CPA) } \\
n=36\end{array}$ & $\begin{array}{l}\text { Anaphylactic shock } \\
\text { Burns, 3rd degree } \\
\text { Drowning } \\
\text { Drug overdose } \\
\quad \text { 1. Anesthesic agents } \\
\quad \text { 2. Triphetamines } \\
\text { General illness } \\
\text { Heart attack } \\
\text { Hemorrhage } \\
\text { Hypothermia } \\
\text { Mechanical injury } \\
\text { No specifics } \\
\quad \text { TOTAL }\end{array}$ & $\begin{array}{r}1 \\
1 \\
1 \\
6 \\
- \\
1 \\
5 \\
- \\
16\end{array}$ & $\begin{array}{l}1 \\
1 \\
- \\
1 \\
- \\
1 \\
5 \\
\frac{3}{1} \\
\frac{1}{13}\end{array}$ & $\begin{array}{l}1 \\
\overline{1} \\
2 \\
- \\
- \\
- \\
3 \\
7\end{array}$ \\
\hline $\begin{array}{l}\text { b. Severe stress (SS) } \\
n=18\end{array}$ & $\begin{array}{l}\text { Diazepam overdose } \\
\text { General illness } \\
\text { Heart attack } \\
\text { Hemorrhage } \\
\text { Mechanical injury } \\
\text { No specifics } \\
\quad \text { TOTAL }\end{array}$ & $\begin{array}{l}- \\
\overline{1} \\
\overline{2} \\
1 \\
4\end{array}$ & $\begin{array}{r}1 \\
5 \\
1 \\
2 \\
1 \\
- \\
10\end{array}$ & $\begin{array}{l}\overline{2} \\
- \\
\overline{2} \\
\overline{4}\end{array}$ \\
\hline $\begin{array}{l}\text { c. Mild stress (MS) } \\
n=7\end{array}$ & $\begin{array}{l}\text { Analgesic } \\
\text { General illness } \\
\text { Mechanical injury } \\
\text { No specifics } \\
\quad \text { TOTAL }\end{array}$ & $\frac{1}{\frac{1}{2}}$ & $\begin{array}{l}- \\
1 \\
2 \\
1 \\
4\end{array}$ & $\begin{array}{l}- \\
- \\
- \\
1 \\
1\end{array}$ \\
\hline $\begin{array}{l}\text { d. Normal (NL) } \\
n=10\end{array}$ & $\begin{array}{l}\text { Asleep } \\
\text { Relaxing } \\
\text { Trance } \\
\text { No specifics } \\
\text { TOTAL }\end{array}$ & $\begin{array}{l}\overline{2} \\
- \\
\overline{2}\end{array}$ & $\begin{array}{l}1 \\
5 \\
1 \\
1 \\
8\end{array}$ & $\begin{array}{l}- \\
- \\
- \\
- \\
-\end{array}$ \\
\hline
\end{tabular}

Characteristics of the Tunnel

Primary identification. Descriptions of the appearance of the tunnel-like space were necessarily limited by the original criteria used to choose the cases: a realistic, enclosed area of space, longer than its diameter. In view of the selection procedure, the fact that 65 percent of the cases identified the enclosed space as a tunnel and 11 percent as a passageway is understandable (see Table 2, row a). 
Table 2

Characteristics of Tunnel Experience

\begin{tabular}{llrr}
\hline \hline \multirow{2}{*}{ Variables } & Description & \multicolumn{2}{c}{ Reports } \\
& Tunnel & Number & Percentage \\
\hline & Passageway, passage & 46 & 65 \\
& Corridor, hall & 8 & 11 \\
a. Primary & Funnel & 6 & 8 \\
identification $^{\text {a }}$ & Shaft & 6 & 8 \\
& Tube & 4 & 6 \\
& Hole & 3 & 4 \\
& Cave & 2 & 2 \\
& Well & 1 & 1 \\
& Sewer & 1 & 1 \\
& Enclosure & 1 & 1 \\
& & 1 & 1 \\
& Long & & \\
& Very long & 22 & 4 \\
& No information & 3 & 4 \\
& & 46 & 65 \\
& Narrow & & \\
& Narrow then widening & 6 & 9 \\
& Wide & 2 & 3 \\
c. Diameter & Wide then narrowing & 1 & 1 \\
& Huge, large & 3 & 4 \\
& No information & 3 & 4 \\
& & 56 & 79 \\
& Dark, black & 32 & 45 \\
d. Illumination & Dimly lit & 3 & 4 \\
& Brightly lit & 4 & 6 \\
& No information & 32 & 45 \\
\hline
\end{tabular}

aSome cases used more than one term to describe the appearance of their TE

Length and diameter. Although the average duration of time spent in the TE was reported as large, 65 percent of the reports did not comment specifically on the length of the space through which they were moving (see Table 2, row b). Thirty-one percent of the cases described the space as "long" and 4 percent experienced it as "very long". No cases reported the space as short or brief.

Few details regarding the space's diameter were obtained (see Table 2, row c), and the 15 descriptions given varied somewhat, with a "funneling" effect being reported in a few cases. Analysis of the cases mentioning diameter yielded no significant interaction between the type of diameter perceived and medical condition or sex. 
Illumination. Impressions of illumination in the enclosed space were frequently general and vague (see Table 2 , row d). Thirty-two cases failed to report on the illumination; of the 39 cases that did, 90 percent used terms such as "dark," "black," or "dimly lit," and 10 percent described their spaces as "brightly lit."

Surfaces of enclosure. None of the 71 cases reported coming into contact with or attempting to touch the surfaces of their enclosed spaces. Seven experients specifically stated that they did nut contact the sides, and some of these explained that they were reluctant or even afraid to try such an action. Only 11 cases mentioned the appearance of the tunnel's surfaces. Despite the fact that all 11 cases mentioning their tunnel's surfaces were in general agreement that they were moving through a long enclosed space, none agreed on what the surfaces looked like. Each case provided a different description: "scintillating darkness," "luminous vapor with mesh of fine lines," "shiny, black, triangular projections," "bricks and a cobblestone floor," etc. This disparity in detail when moving from the general (for which the cases were selected) to the specific is a common feature in these experiences, raising important questions that will be discussed later.

\section{Phenomena Encountered in Tunnel Experience}

Light phenomena. An area of light in the center or at the end of the space was described by 30 cases ( 42 percent). Of those cases reporting a light, 22 (73 percent) experienced it as becoming larger in their field of vision and described themselves as moving toward the light rather than the light moving toward them.

Although 30 cases did mention a light, many failed to provide details of its appearance. Fourteen reported the intensity of the light as "bright," "brilliant," "dazzling," "radiant," or "shining," yet none of these experients mentioned any visual discomfort to the brightness, and 2 cases remarked on this fact. The color of the light varied, being described as "white," "yellow-white," "like a flash bulb" or "tungsten flame," "golden," "red," or "bluish." Two cases added that the light was "warm."

Eleven cases reported very positive feelings toward the light, 2 cases felt fearful of it, while the remaining 17 did not mention any emotional reactions. Twenty-five reports did not identify the nature of the light, but 2 cases felt it was Christ, and 3 cases saw the light in the shape of an unidentified human being.

Of the 14 men, 12 women, and 4 cases of unknown gender reporting light phenomena, no significant relationship could be found 
in their distributions. All medical conditions were represented to some extent in these cases, with no exceptional distributions.

Colors. Of the 13 cases reporting color, 8 described the color of the light they saw. One case experienced a dark redness above and a dark blueness in front of her that gradually became brighter and varied until finally the colors and sounds synesthetically combined into a "wonderful music." An orange-red light seemed to reflect on the walls of one experient's tunnel, although he could not determine its source. Three cases described areas of color as if these were floating in the tunnel: one case described it as profound colors streaking by him as he moved forward, another saw multi-colored small bright flashes of light around him, while the third case reported patches of various colors passing between him and a light at the end of his tunnel.

Sounds. Only 18 cases (25 percent) reported hearing sounds during the TE, with 4 of these hearing more than one sound. Simple noises such as swishing, humming, distant voices, wailing, ringing, and moaning were reported by 11 experients. All cases hearing simple noises were in the CPA or SS categories undergoing medical conditions associated with rapidly falling blood pressure (e.g., heart failure, hemorrhaging, and anaphylactic shock). Twelve of the 18 individuals reported complex sounds such as music, or voices which sometimes told them to return to life.

Beings and obstacles. Only 8 cases (11 percent) reported encountering something resembling a living being in their TEs. Three cases described a brightly lit human form, while the remaining 5 cases described dissimilar entities: a grotesque giant, the husband of the percipient calling her to return to life, two women dressed in white, an old man traveling ahead down the tunnel, and a surrounding field of figures changing from monstrous to peaceful forms.

Six of the 71 cases were prevented at some point in their TEs from moving further, though the causes of these stoppages varied considerably. No agreement was found among experients concerning beings and obstacles encountered in their TEs.

Temperature. Five cases mentioned a comfortable feeling of warmth in their TEs, with 2 of these associating the warmth with a light at the end of their tunnels. One case experienced an unpleasant coldness and felt that she would get warm if she reached a golden light at the end.

Emotion/pain. Emotional reactions to the TE were generally passive or calm. However, 15 cases (21 percent) reported some degree of strong positive affect, e.g., peace, delight, joy, and happiness, and this emotion was occasionally associated with a release 
from physical pain, a light at the end of the tunnel, or a heightening sense of expectancy. Negative affect, e.g., fear, panic, and sadness, was reported by 8 cases ( 11 percent); however, 2 of these experienced an initial fear upon entering the TE but began to feel happy and peaceful as the experience progressed. Two cases reported feeling physical pain in their TEs, and 2 cases experienced the narrow diameter of their tunnels as being uncomfortably tight.

\section{Movement of Experient}

Direction. The sensation of moving through the TE was described by 67 cases ( 94 percent); the remaining 4 ( 6 percent) reported they were stationary. Of those cases reporting movement, 14 described themselves as moving down through the tunnel, 5 as rising up through the tunnel, while the majority ( 48 cases) reported their movements as going through the tunnel, indicating or implying in most instances that the direction appeared to be on a horizontal plane. No significant relationships were found between direction of movement and medical condition or sex.

Speed. Of the 67 cases reporting movement, 31 were unclear concerning their speed, 12 described themselves as moving at a "slow" to "moderate" speed (e.g., floating, rising, walking), and 24 experienced themselves as moving very fast.

Volitional control. Fourteen cases seemed able to influence their movement through the tunnel. Of these cases, a significant difference was found between the sexes, with 11 of the 14 being female and only 1 male, while the gender of 2 cases was unknown (chi square (1) = $6.75, \mathrm{p}<.01)$. The distribution of sexes $(21$ males and 23 females, with 9 unknown) in the 53 cases not reporting the ability to influtheir movement was not significant.

Going and returning. The experience of moving in only one direction was reported by 59 cases, whereas the other 8 cases described moving through the tunnel a second time in the context of "returning" to normal life. All 8 cases indicated a complete reversal in their original direction.

\section{Peripheral Elements}

TEs normally occur in unusual experiences containing other elements. Although it is not the purpose of this study to examine experiential elements other than the TE, it will be useful to look at those elements immediately preceding and succeeding the TE as possibly offering clues to the nature of these experiences.

Elements preceding the TE. The TE was the first experiential 
element for 44 cases (62 percent). Of the 27 cases reporting an element preceding their TE, 20 had a simple out-of-body experience (SOBE) immediately before the TE. That is, they found their center of perception floating above or near their physical bodies with no complex phenomena such as otherworldly beings, "flying" to distant places, or trying to interact with the physical environment. ${ }^{7}$ The remaining 7 cases described more elaborate and dissimilar experiences preceding the TE.

No clear picture arises from these reports. Although SOBEs account for 74 percent of those cases reporting preceding experiential elements, they are very frequent in unusual experiences not entailing TEs, and thus their occurrence in this context can only be considered as possibly suggestive of a pattern.

Entering the tunnel. The majority of cases experienced no preceding elements or sense of logical transition to their TEs, i.e., they were just suddenly "there." Five cases, however, did report encountering an entrance to their tunnels. In 4 of these cases, the experients were undergoing an SOBE above their bodies, and in the fifth case there was simply a sensation of floating. None of the cases gave any specifics concerning the tunnel entrance.

Exiting the tunnel. The experience of leaving the tunnel as if passing through an opening at the far end was described by 20 cases. As with the cases reporting an entrance to the tunnel, those cases exiting gave no details concerning the appearance of the exit. Nineteen cases experienced no exiting from the tunnel, suddenly finding themselves no longer in the tunnel but in different surroundings. Thirty-two cases reported nothing following the TE (i.e., they returned to normal consciousness or could not remember any thing else).

Elements subsequent to a TE. Of the 39 cases who reported experiential elements following their TE, considerable variation existed and no consistent theme could be found among the descriptions. Six experients mentioned leaving their tunnels to enter various versions of a brightly illuminated but empty space, in which 3 cases sensed the "presences of others," 2 encountered human figures, and 1 traveled to an area where she was able to view a garden. Four cases reported out-of-body experiences following their TEs (2 SOBEs and 2 COBEs), and 4 cases found themselves in scenes with a hellish theme. ${ }^{8}$ Unique scenes were reported by 12 cases: a light blue universe; a mouthless figure leading the way over a bridge; a stream of people; a bare room with dead relatives; a room or box-like area in mist; an empty room; a desert of a "lower-order world"; a celestial city; fantastic landscapes that changed with the experient's thoughts; a "spiritual sphere"; scenes of the experient's past; and an encounter 
with a deceased relative with no mention of surroundings. Thirteen cases reported a natural scene of some kind: 10 experients found themselves in country settings, e.g., meadows, fields, valleys, (but all the scenes were different); of the other natural scenes, one involved a beach with a wall of vegetation, another a seascape, and the other a desolate area spotted with rocks.

Dead friends and relatives were encountered by 6 of the 10 cases experiencing a country scene, as well as by the case describing a celestial city and the one mentioning a bare room.

\section{DISCUSSION}

\section{Salient Results}

Using the more frequently occurring features found in this study, we can construct the following composite of a typical TE.

The TE is often the first element in an unusual experience, and its occurrence is usually abrupt. If an element precedes the $T E$, it is most frequently a simple out-of-body experience (SOBE). TE characteristics do not differ among the medical conditions studied, although they are more often found in association with the more serious conditions (excepting cancer and stroke). Men and women are equally likely to report a TE, and the majority of experients feel that the terms "tunnel" or "passageway" adequately describe what they have perceived. The sensation of movement, usually in only one direction, is almost always reported, and the tunnel interior is typically long and either dark or dimly lit. Slightly less than half the cases report a light or luminous object in the center or at the end of their tunnel-like spaces. Descriptions of elements subsequent to the TE are reported by only half of the experients and display little inter-subject agreement.

The occurrence of TEs in only 13 percent of the CPA and SS categories, and in only 9 percent of the total categories, leads to the conclusion that this element is not a typical characteristic of the average near-death or out-of-body experience. The disagreement between the details of the TE reports is the most salient and surprising finding of this study. Studies such as this one have been undertaken because the descriptions of these various unusual experiences display impressive similarities, which may differentiate them from the normal range of psychopathological subjective events. However, the inter-individual variations in the descriptions of specifics of TEs raise serious questions that cannot be explained by simple differences in individual viewpoints and interpretations. 


\section{Symbols of Transition in Myth and Ritual}

The presence of the TE in a variety of conditions suggests that it may be a universal theme, perhaps in the sense of Bastain's (Campbell, 1959) "elementary ideas" or Jung's (1959) “archetypes." Gennep, in his famous book, The Rites of Passage (1961), observes that the symbol of passing through a defined area such as a gate or portal is almost universally held to represent a transition from one realm or condition to another. Caves or tunnels are, however, only one example of a multitude of forms used to represent passage themes in mythologies and in the rituals of birth, initiation, marriage, and death (Jung, 1968; Levy, 1948).

Cultures such as the Babylonian and Greek, which located their afterworlds deep underground, naturally viewed caves, chasms, and burrows as means of access to these realms, but such forms of entry clearly do not precisely parallel the TE. The idea that the soul of the shaman (Eliade, 1964) or the dead must pass through areas or trials before reaching the other world is widespread, but roads, bridges, and rivers rather than tunnels are the predominant mode of transit (Eliade, 1967). Although the descriptions found in The Tibetan Book of the Dead (1975) show some impressive parallels with neardeath experiences, no mention can be found of anything approximating a TE. A suggestive description of the soul of the dead passing through holes in the sky, the sun, and the moon can be found in the tenth Brahmana of the Brhad-Aranyaka Upanisad (Radhakrishnan, 1953), but the passage is unclear and may only refer to a Pythagorean purging of the soul by passage through the various elements.

Examination of eschatological mythologies leads to the conclusion that in general the TE is not in evidence in these beliefs about the afterlife.

\section{Drug-related TEs}

TEs were common events in connection with anesthetic experiences until fairly recently (Smith, 1972). One early researcher (Dunbar, 1905) found that 80 percent of the surgical patients he interviewed experienced singing in the ears, rushing into a dark tunnel, and a flashing of lights in the eyes.

The following ether experience illustrates this common phenomenon: "I seemed to float down a dark tunnel moving towards a halfmoon of light that was miles away. I heard the sound of music and smelled the scent as of an old-fashioned bouquet. Then my flight down the tunnel was halted . . . A voice said, 'Go back and live.' Then I found myself back in the body" (Crookall, 1976, p. 119). 
The beautiful smells and complex sounds so often reported in the anesthetic experience are usually found to be illusory elaborations of the unpleasant odor of the anesthetic, and the ringing or buzzing in the ears (tinnitus) caused by the anesthetic. Bizarre experiences of spinning, flying, or falling are typically attributed to the sensations of vertigo produced by the anesthetic. In contrast to the frequency of early reports, recent studies of the incidence of mental aberrations associated with general anesthesia reveal an extremely low frequency of dreams and hallucinations, and no reports of tunnels (Browne and Catton, 1973; Wilson, Vaughan, and Stephen, 1975). This lack of contemporary reports is attributable to the modern trend in anesthesiology of using sophisticated techniques to provide complete amnesia while maintaining adequate analgesia (Cherkin and Harroun, 1971). As a result, little modern systematic knowledge has been collected on the phenomenology of anesthetic states. The similarities between elements such as TEs reported in NDEs and OBEs and those found in anesthetic hallucinations (Muldoon and Carrington, 1951; Moore and Alltounian, 1978; Shedlin, Wallechinsky, and Salyer, 1973; Smith, 1972), strongly suggest a common mechanism as well as the prospect of using anesthetics (e.g., ether, chloroform, ketamine, nitrous oxide, etc.) to investigate this mechanism.

Meduna (1950) also found many of his patients reported experiences of tunnels, cones, and bright lights while undergoing a therapeutic inhalation of a mixture of 30 percent carbon dioxide and 70 percent oxygen. The following is a typical experience of $\mathrm{CO}_{2}$ narcosis involving a tunnel:

I seemed to see a bright white light at the end of a long tunnel, and had an intense feeling that it would be wonderful if I could only reach it. I couldn't get to it before the effects of the gas wore off, but I felt very excited and exhilarated (Johnson, 1959, p. 157).

The similarities between $\mathrm{CO}_{2}$ narcosis and LSD are so close that the subject's reaction to carbon dioxide inhalation can be used as a prognostic tool before LSD sessions (Grof and Halifax, 1977). Over the years many investigators have noted that the imagery of hallucinations is basically the same whether induced by stress, drugs, or a variety of other conditions. ${ }^{9}$ Kluver (1942) referred to the simpler common images as "form-constants" and observed that many "atypical" visions were, upon closer examination, nothing but variations of these form-constants. He described four types of formconstant: (1) grating, honeycomb, or lattice; (2) cobweb; (3) tunnel, funnel, or alley; and (4) spiral. The development of hallucinatory imagery has been found to demonstrate a consistent pattern of 
sequential development beginning with the simple form-constants, which are gradually elaborated into faces and static objects and then into landscapes and more complex and prolonged scenes (Richardson, 1969; Schacter, 1976). An example of this type of elaboration with the tunnel form-constant is found in the reports of some of Meduna's (1950) patients, who began by experiencing circles which then "pulled out" into straight tubes or funnels as the effects of the gas increased.

Circular tunnel-like forms are particularly prevalent in hallucinogenic drug experiences. In his experiments with peyote, Kluver (1926) noted that the center of his visual field was of ten distinguished from the remainder of the field, being frequently similar to "the interior of a cone, the vortex of which is lying in the center of the field directly before the eyes" (p. 503). This commonly reported effect was systematically explored by Siegel (1973) and Siegel and Jarvik (1975) in experiments with marijuana, THC, LSD, psilocybin, and mescaline. They found that the imagery was usually characterized by a very bright light in the center of the visual field; the locus of this light created a tunnel perspective, and subjects commonly reported viewing their imagery in relation to a tunnel.

Certainly in some ways the elaborated drug-induced form-constant of a tunnel seems to resemble the TEs examined in our study. There are, however, notable deviations such as complex imagery moving in the periphery of the visual field, which often involves recognizable landscapes, people, and objects. In the early stages of the hallucinogenic session, the subject is usually aware of the unreality of the tunnel and continually changing imagery, but as the state deepens he begins to accept the reality of the complex imagery and becomes part of what he was previously merely observing (Siegel and Jarvik, 1975).

The occurrence of tunnel forms in conditions such as anesthesia, carbon dioxide inhalation, and hallucinogen ingestion, contributes an important finding to our analysis. Although there are differences in the characteristics of TEs under some of these conditions, the similarities are clear enough to suggest strongly the idea that the same event is occurring in all of these conditions, and that variations are merely reflective of etiological peculiarities. Often the only difference between an unreal tunnel-like image and a realistic TE is the individual's ability to discriminate between literal and analogous meanings, i.e., a thin cognitive line exists between the point where the experient still perceives an image in terms of "as if" and where he begins to experience it as reality (McKellar, 1957; Reed, 1972). I be- 
lieve sufficient evidence exists to support serious consideration of the hypothesis that a common mechanism underlies both the TEs examined in this study and those similar experiences associated with the other conditions discussed in this section.

\section{Explanatory Theories}

As the TE gives the impression of passing through an area, the majority of theories suggested to explain the experience assumes that it is a transition of some kind, either between two different conditions of existence or of consciousness. I will now discuss several of these theories and examine their explanatory value in view of the results of the present study.

Objective explanations. Explanations assuming an objective reality to the tunnel are normally based on a conception of the otherworld as lying deep underground, and that the soul journeys to it through actual caves and holes in the earth's surface (such as the famous cave at the lake of Avernus, near Naples). Some spiritualists and occultists contend that the tunnel is a shield to protect the soul as it passes through the lower, possibly dangerous, astral realms.

Representational explanations. The majority of theories does not argue for an objective reality to the tunnel, but instead advocates a representational interpretation, which is based on the premise that the sensing mind does not have direct acquaintance with the objective event but apprehends it symbolically through images and ideas.

The representational approach has often been used to explain contradictions and unrealities in a variety of altered states. In her classic study of mysticism, Underhill (1961, p. 271) concluded that many of the disharmonies noticeable in visionary experiences are explicable as forms of symbolic expression of real spiritual experiences that would be incomprehensible to the conscious mind if directly perceived. Osis and Haraldsson (1977) in their study of deathbed experiences reached a similar position when confronted with the bewildering variety of imagery in their cases and suggested that the images are probably symbolizations pointing to an existence not congruent with our perceptual capabilities. Whiteman's (1961) years of personal experience with OBEs and mystical states led him to a similar representational interpretation of the content of these states. $\mathrm{He}$ argued that the TE is a fantasy representation of very different deeper mental conditions having an objective basis (Whiteman, 1956).

Green (1968) suggested that OBEs involving falling or traveling along a tunnel are representations of long displacements in space, possibly including a displacement in time. Shirley (1972) viewed the 
tunnel experience as a symbolic production of the subconscious in order to represent movement out of the body. The association of the TE with the separation process of body and $\mathrm{mind} / \mathrm{soul}$ is a prevalent idea among theorists. Crookall (1970) postulated that during separation there is a "blackout" of consciousness when neither the soul body nor the physical body is available as an instrument of awareness of either the physical world or the "next world." When it is brief, the transition is experienced as merely a blank; if the process takes slightly longer, it is symbolized by the subconscious as passing through a tunnel or vast space.

Ring (1980a) and Bentov (Ring, 1980a) argue that the TE is a psychological phenomenon whereby the mind experiences a shift from the body's sensory-based state of consciousness to a holographic or four-dimensional consciousness of pure frequencies. The gap in time while this shift is occurring is experienced as movement through a dark space. Bentov (Ring, 1980a) also suggested that once this shift becomes habitual it becomes instantaneous, and then there is no longer any need for a TE. His idea is especially interesting since a similar conclusion was reached independently by one of the men in the study who had frequent OBEs during which he traveled down a long tunnel to visit dead friends. After a number of years he no longer traversed a tunnel, finding himself "instantly" with his friends. $\mathrm{He}$ felt that the tunnel never actually existed, but was a required illusion while one was learning.

The final theory with which I shall deal is the argument that the TE is a transition represented to awareness using memories of the individual's physical birth (Rogo, 1978,pp. 317-319; "Theta Forum," 1978). As the higher centers of the fetal brain are not functioning at birth, it is difficult to understand how this memory of the birth process could exist for such retrieval. In any case, the theory is confounded by the dissimilarity between the typical TE and the physiologically traumatic passage through the birth canal, which involves tremendous crushing pressures and suffocation (Lefrancois, 1977).

The disparate descriptions of details in the TE reports weigh heavily against those theories that argue for the tunnel as an objective reality while it is this very diversity that would seem to encourage representational speculation. If we examine these explanations more closely, however, we find that none is currently testable. The theories require the assumption that some form of change or transition is taking place, yet there is no reason beyond the imagery of the TE itself to think that such an event is actually occurring. Most of the theories fail to mention what mechanisms are involved in the representational process or why the process generates the forms 
it does. As the objective event itself remains undefined in most cases, we are left with little or no explanation of the representative relationship, i.e., is it metaphorical, or one of correspondence, or entirely fantasy? Without definite statements about the representational processes, these theories have only small explanatory value and are of little use in research.

The fact that 28 percent of the cases reported an SOBE before their TEs would seem to suggest that Shirley's and Crookall's identification of tunnels with separation is incorrect. When they did occur, the elements subsequent to the TE were too disparate to offer support for those theories that expected the tunnel to lead to a particular level of consciousness or existence. Only a condition approximating the illusory (ideoplastic) state of the Tibetan Chönyid Bardo would seem to account for the diversity of circumstances encountered after the TE. Large scale studies of otherworldly environs reported in unusual experiences may find common patterns and themes, but in this study there is no indication of a coherent phenomenon at the end of the tunnel and little direct evidence that the tunnel is a transition of any sort.

The development of a theory for the TE that specified the supposed event taking place and postulated a definite representational process could provide a considerable impetus to future research. In view of the findings in this study, current representational explanations tend to create far more questions than they answer.

A psychophysiological explanation. In view of the results of this study, there is good reason to assume that the TE is not a form of transition and most probably has no objective dimension at all. I believe the evidence leads to the conclusion that the TE is an hallucinatory event. To support this view, I would like to present the following explanation using a psychophysiological model.

Perception is a continuing process of information gathering, processing, and decision making, which is highly reliant on the reliability of incoming stimuli and the brain's discriminative and organizing abilities. The brain is constructed to make sense of whatever information it is presented, and perception can therefore be considered its "best guess" as to what stimuli mean. When information sources are limited, in conflict, or supply unusual patterns of stimuli, the perceptual process persists in its attempts at interpretation, and the results are errors in perception such as illusions or hallucinations (Gregory, 1966; Reed, 1972).

Man's dependency on visual information over other sources renders his assessment of reality particularly vulnerable to injuries or transient disturbances in this system. Although the brain's judgments 
as to body location and movement are informed by nervous feedback from the visual, vestibular, proprioceptive systems (Waterbor, 1979), visual inputs - even when supplying blatantly incorrect information - will tend to override more reliable inputs from all the other sources. A good illustration of this can be found in the illusion of "induced motion," which is especially evident in the false movement felt when the train on a neighboring track pulls out (Wallach, 1972).

In situations in which reliable exterioceptive stimulation is decreased or distorted, the brain's recruitment of information becomes more desperate. Those conditions that tend to disrupt external information flow are usually associated with (1) a diminished capacity to discriminate reliable from unreliable data and (2) increased cortical arousal (Lipowski, 1980; Winters, 1975). This disorganization of perceptual functioning is prevalent in many situations, including the medical conditions examined in this study as well as anesthetic states, $\mathrm{CO}_{2}$ narcosis, and hallucinogenic drug states.

Some writers have argued that the uniqueness of the unusual experiences found in many near-death situations lies in their occurrence during a period when the subject is unconscious and therefore should not be experiencing anything. It would be a mistake to assume that a lack of responsiveness is indicative of a depressed central nervous system; an individual undergoing coma, delirium, sleep, convulsions, or forms of temporary unconsciousness may well be in a hyperaroused state and yet be cut off from, and hence unresponsive to, external stimuli (Fischer, 1971; Winters, 1975). Few of the cases in this study reported any awareness of external stimuli during their TEs, and Ring (1980a) found the majority of his cases reported either totally absent bodily sensations or a sense of bodily lightness. Although external stimulation is decreased, reports of NDEs and OBEs generally describe feelings of alertness and even superawareness, which very probably reflect the hyperattentiveness of cortical arousal coupled with a narrowing range of sensory and ideational stimuli (Fischer, 1971; Silverman, 1971).

In this study the medical conditions associated with TEs tended to be acute. Perceptual disturbances have been found to be much more probable in situations involving such sudden changes in the physicochemical milieu of the brain, whereas patients suffering from chronic conditions show little or no evidence of cognitive dysfunction as they seem to undergo the same changes over an extended period of time and can thus adapt gradually (Lipowski, 1980, pp. 152-154).

Deprived of reliable stimuli, the brain's increasing need for information combined with its decreased discriminative powers results in the use of normally ignored or inhibited internal stimuli sources. ${ }^{10}$ 
In its search, the perceptual process may become sensitized to "noise" and transitory disturbances in different levels of the nervous system. Preference will always be given to information from the visual pathway, regardless of how contradictory or vague it may be. These anomalous inputs tend to be experienced by the brain in certain patterns though it remains unclear whether these patterns are isomorphic reflections of nerve excitation (Richards, 1972) or expressions of the mind's propensity for organizing random stimuli in meaningful ways. These patterns are visually perceived as the simple form-constants discussed earlier, e.g., tunnels, spirals, and lattices (see Barber, 1970, pp. 26-34; Horowitz, 1964; and Siegel and Jarvik, 1975 for an extensive examination of this process). These formconstants, particularly tunnels and spirals, then serve as sensory cores or niduses around which complex images and hallucinations are elaborated (Horowitz, 1975).

Because of the impaired interpretative ability of the discriminative function, the imaginative processes of the unconscious come to provide the elaboratory mechanism. The unconscious considers similarity as the equivalent of identity, so a simple tunnel form-constant becomes imbued with a realistic dimension creating an hallucinatory perception. Although the general features of the tunnel are determined by a commonly shared perceptual tendency, the details of the hallucination are left to the unique elaborations of each individual's unconscious, hence the large variations in specifics found in TE descriptions.

Disturbances of the vestibular system, such as vertigo, are common in many disruptive conditions (Merck Manual, 1977), and these illusions of movement are probably used by a disorganized perceptual process either to create an elaborated TE or augment elaborations on an already existent tunnel form-constant. Sounds would also be elaborations of tinnitus, e.g., simple sounds such as humming or ringing that originate in the middle ear (Saravay and Pardes, 1970; Segal, 1971).

Those components that seem to comprise the tunnel hallucination, such as dark visual fields, lights, movement, and tunnel forms, are found in many types of unusual experiences, yet the events that bring them together seem fairly rare, as this study shows.

Although I have noted that TEs tend to be associated with acute crises, there would appear to be an unknown factor in the etiologies of certain conditions that makes the TE more probable, e.g., clinical death conditions or $\mathrm{CO}_{2}$ narcosis. I would conjecture that sudden disturbances in the vestibular cerebellar system may well play a crucial role in producing the TE. 


\section{CONCLUSION}

The results of this study have led me to conclude that the experience of moving through a tunnel-like space is merely an hallucinatory creation of the mind. The explanation I have presented does not differ in principle from the one suggested by Siegel $(1980 ; 1981)$. Unlike Siegel, however, I would confine this theory solely to explaining the TE and not propose it as a gencral explanation of all elements in NDEs or OBEs.

Although the TE would appear to have no objective basis outside the experient's nervous system, this conclusion cannot be indiscriminately extended to other elements such as otherworldly environs, SOBEs, light phenomena, and mystical unity. I have argued in an earlier paper (Drab, 1981) that the NDE may well be comprised of a number of contiguous yet independent discrete states of consciousness and minor perceptual disturbances. I propose that these unusual experiences are far too complex for blanket theories and that it will be far more productive to examine and evaluate the worth of each element separately from the rest. The results of such an approach may support Siegel's hallucinatory explanation or lend credence to my own conjecture that at least some of these unusual experiences are amalgams of psychopathological, psychological, and parapsychological phenomena (Drab, 1981).

\section{NOTES}

1. Excerpt from CPA case No. 26, interview by K. Drab with Mrs. R. W. O. on July 15, 1976.

2. A number of Crookall's cases were not used due to their duplication, misquotation, and inappropriate classification.

3. Excerpt from MS case No. 91, as reported in Fiore and Landsburg, 1979.

4. The medical categories are described in detail since it is hoped that this classification will prove useful to other researchers.

5. The term "stress" is used in the physiological sense as any stimulus that creates an imbalance in the homeostatic state of the organism's internal environment. The stress may originate from the external environment, e.g., in the form of injury, infection, lack of oxygen, or excesses of temperature; or the stress may originate within the body, e.g., in the form of high blood pressure, pain, tumors, or excesses of CNS arousal (Tortora and Anagnostakos, 1978). 
6. This finding agrees with the results of a recent study (Gabbard, Twemlow, and Jones, in press), which also found a much higher incidence of tunnel experiences in association with NDEs than in OBEs not occurring in near-death conditions.

7. The use of the terms SOBE and complex out-of-body experience $(\mathrm{COBE})$ is a convenient way of distinguishing between the far more common experience of "separating" briefly from the body and "separations" entailing a variety of more complicated and extended phenomena.

8. It should be mentioned that 3 of these cases encountering hellish scenes were from a collection of rather atypical NDE reports in M. Rawlings' Beyond Death's Door. New York: Thomas Nelson, 1978.

9. See the excellent review of the literature in Siegel and Jarvik, (1975).

10. These internal sources may include psychodynamic, ontogenetic, and phylogenic, as well as parapsychological information. The TE is considered to be based on fairly superficial stimuli, hence the present discussion does not consider deeper sources.

\section{REFERENCES}

Barber, T. X. LSD, Marihuana, Yoga, and Hypnosis. Chicago: Aldine, 1970.

Barrett, W. Death-bed Visions. London: Methuen \& Co., 1926.

Browne, R. A. and Catton, D. V. Awareness during anesthesia. Anesthesia and Analgesia, 1973, 52, 128-132.

Campbell, J. The Masks of God: Primitive Mythology. New York: Viking Press, 1959.

Cherkin, A., and Harroun, P. Anesthesia and memory processes. Anesthesiology, 1971, 34, 469-474.

Crookall, R. The Supreme Adventure. Cambridge, England: J. Clarke \& Co., 1961.

Crookall, R. The Techniques of Astral Projection: denouement after Fifty Years. Northamptonshire, England: Aquarian Press, 1964.

Crookall, R. Out-of-the-Body Experiences: a Fourth Analysis. Secaucus, N.J.: Citadel Press, 1970.

Crookall, R. The Study and Practice of Astral Projection. Secaucus, N.J.: Citadel Press, 1976.

Drab, K. J. Unresolved problems in the study of near-death experiences: some suggestions for research and theory. Anabiosis, 1981, $1,27-43$. 
Dunbar, E. The light thrown on psychological processes by the action of drugs. Proceedings of the Society for Psychical Research, 1905, 19, 62-77.

Eliade, M. Shamanism: Archaic Techniques of Ecstasy. Princeton, N.J.: Princeton University Press, 1964.

Eliade, M. (Ed.). From Primitives to Zen. New York: Harper \& Row, 1967.

Fiore, C. and Landsburg, A. Death Encounters. New York: Bantam Books, 1979.

Fischer, R. A cartography of the ecstatic and meditative states. Science, 1971, 174, 897-904.

Gabbard, G. O., Twemlow, S. W., and Jones, F. C. Do near-death experiences occur only near death? Journal of Nervous and Mental Disease, in press.

Garfield, C. A. More grist for the mill: additional near-death research findings and discussion. Anabiosis Newsletter, 1979, 1(1), 5-7.

Gennep, A. van The Rites of Passage (M. B. Vizedon and G. L. Caffee, trans.). Chicago: University of Chicago Press, 1961.

Green, C. Out-of-the-Body Experiences. London: Institute of Psychophysical Research, 1968.

Gregory, R. L. Eye and Brain: the Psychology of Seeing. New York: McGraw-Hill, 1966.

Grof, S. and Halifax, J. The Human Encounter with Death. New York: Dutton, 1977.

Horowitz, M. J. The imagery of visual hallucinations. Journal of Nervous and Mental Disease, 1964, 138, 513-523.

Horowitz, M. J. Hallucinations: an information-processing approach. In R. K. Siegel and L. J. West (Eds.), Hallucinations: Behavior, Experience, and Theory. New York: Wiley \& Sons, 1975.

Johnson, R. C. Watcher on the Hills. London: Hodder \& Stoughton, 1959.

Jung, C. G. On the nature of the psyche. In V. S. de Laszlo (Ed.), The Basic Writings of C. G. Jung. New York: Modern Library, 1959.

Jung, C. G. (Ed.). Man and his Symbols. New York: Dell, 1968.

Kluver, H. Mescal visions and eidetic vision. American Journal of Psychology, 1926, 37, 502-515.

Kluver, H. Mechanisms of hallucinations. In Q. McNemar \& M. A. Merrill (Eds.), Studies in Personality. New York: McGraw-Hill, 1942.

Krippner, S. Psychedelic experience and the language process. Journal of Psychedelic Drugs, 1970, 3(1), 41-51. 
Lefrancois, G. R. Of Children: An Introduction to Child Development. Belmont, Ca.: Wadsworth, 1977.

Levy, G. R. The Gate of Horn. London: Faber \& Faber, 1948.

Lipowski, Z. J. Delirium: Acute Brain Failure in Man. Springfield, Ill.: Charles C. Thomas, 1980.

McKellar, P. Imagination and Thinking. New York: Basic Books, 1957.

Meduna, L. J. Carbon Dioxide Therapy. Springfield, Ill.: C. C. Thomas, 1950.

Merck Manual (13th ed.). Rahway, N.J.: Merck \& Co., 1977.

Moody, R. A. Life After Life. Atlanta, Ga.: Mockingbird Books, 1975.

Moore, M. and Alltounian, H. Journeys into the Bright World. Rockport, Ma.: Para Research, 1978.

Muldoon, S. J. and Carrington, H. The Projection of the Astral Body. London: Psychic Book Club, 1929.

Muldoon, S. J. and Carrington, H. The Phenomena of Astral Projection. London: Rider \& Co., 1951.

Myers, F. W. H. Human Personality and its Survival of Bodily Death (Vols. 1 \& 2). New York: Longmans, Green, \& Co., 1903.

Osis, K. and Haraldsson, E. At the Hour of Death. New York: Avon Books, 1977.

Radhakrishnan, S. (Ed. and trans.). The Principal Lpanisads. London: Allen \& Unwin, 1953.

Reed, G. The Psychology of Anomalous Experience. London: Hutchinson \& Co., 1972.

Richards, W. The fortification illusions of migraines. In Perception: Mechanisms and Models. San Francisco: Freeman \& Co., 1972.

Richardson, A. Mental Imagery. New York: Springer-Verlag, 1969. Ring, K. Life at Death. New York: Coward, McCann \& Geoghegan, 1980. (a)

Ring, K. Personal Communication, December 17, 1980. (b)

Rogo, D. S. (Ed.). Mind beyond the Body. New York: Penguin Books, 1978.

Sabom, M. B. and Kreutziger, S. A. Physicians evaluate the neardeath experience. Theta, 1978, 6(4), 1-6.

Saravay, S. M. and Pardes, H. Auditory 'elementary hallucinations' in alcohol withdrawal psychoses. In W. Keup (Ed.), Origin and Mechanisms of Hallucinations. New York: Plenum Press, 1970.

Savage, C. W. The continuity of perceptual and cognitive experiences. In R. K. Siegel and L. J. West (Eds.), Hallucinations: Behavior, Experience, and Theory. New York: Wiley \& Sons, 1975. 
Schacter, D. L. The hypnagogic state: A critical review of the literature. Psychological Bulletin, 1976, 83, 452-481.

Segal, S. J. Processing of the stimulus in imagery and perception. In S. J. Segal (Ed.), Imagery: Current Cognitive Approaches. New York: Academic Press, 1971.

Shedlin, M., Wallechinsky, D., and Salyer, S. (Eds.). Laughing Gas: Nitrous Oxide. Berkeley, Ca.: And/Or Press, 1973.

Shirley, R. The Mystery of the Human Double. New York: Olympia Press, 1972.

Siegel, R. K. Visual imagery constants: drug-induced changes in trained and untrained observers. Proceedings of the 81st Annual Convention of the APA, 1973, 8, 1033-1034.

Siegel, R. K. The psychology of life after death. American Psychologist, 1980, 35, 911-931.

Siegel, R. K. Accounting for 'afterlife' experiences. Psychology Today, January, 1981, 65-75.

Siegel, R. K. and Jarvik, M. E. Drug-induced hallucinations in animals and man. In R. K. Siegel and L. J. West (Eds.), Hallucinations: Behavior, Experience, and Theory. New York: Wiley \& Sons, 1975.

Silverman, J. A paradigm for the study of altered states of consciousness. Journal of Psychedelic Drugs, 1971, 3, 89-103.

Smith, P. B. Chemical Glimpses of Paradise. Springfield, Ill.: C. C. Thomas, 1972.

Theta forum (published correspondence between W. Roll and K. Drab). Theta, 1978, 6, 29-30.

The Tibetan Book of the Dead (F. Fremantle and C. Trungpa, trans.). Berkeley, Ca.: Shambhala, 1975.

Tortora, G. J. and Anagnostakos, N. P. Principles of Anatomy \& Physiology (2nd ed.). New York: Harper and Row, 1978.

Underhill, E. Mysticism. New York: Dutton, 1961.

Wallach, $\mathrm{H}$. The perception of motion. In Perception: Mechanisms and Models. San Francisco: Freeman \& Co., 1972.

Waterbor, R. Experiential bases of the sense of self. Journal of Personality, 1979, 40, 162-179.

West, D. J. The investigation of spontaneous cases. Proceedings of the Society for Psychical Research, 1948, 8, 264-300.

Whiteman, J. H. M. The process of separation and return in experiences fully 'out-of-the-body'. Proceedings of the Society for Psychical Research, 1956, 50, 240-274.

Whiteman, J. H. M. The Mystical Life. London: Faber \& Faber, 1961.

Wilson, S. L., Vaughan, R. W., and Stephen, C. R. Awareness, dreams and hallucinations associated with general anesthesia. Anesthesia and Analgesia, 1975, 54, 609-617. 
Winters, W. D. The continuum of CNS excitatory states and hallucinosis. In R. K. Siegel and L. J. West (Eds.), Hallucinations: Behavior, Experience, and Theory. New York: Wiley \& Sons, 1975.

Requests for reprints to:

Kevin J. Drab

$101 \mathrm{~N}$ Street

NAS Agana

FPO San Francisco, California 96637 